\title{
Proximal Femur Size and Geometry in Cementless Total Hip
}

\section{Arthroplasty Patients [version 1; peer review: 1 approved, 1}

\section{approved with reservations]}

\author{
Darrell L. Moulton, Ronald W. Lindsey (iD), Zbigniew Gugala (iD
}

Department of Orthopaedic Surgery and Rehabilitation, The University of Texas Medical Branch, Galveston, TX, 77555-0165, USA

V1 First published: 23 Jun 2015, 4:161

https://doi.org/10.12688/f1000research.6554.1

Latest published: 23 Jun 2015, 4:161

https://doi.org/10.12688/f1000research.6554.1

\section{Abstract}

Introduction: Accurate femoral prosthesis press-fit is essential for successful cementless total hip arthroplasty (cTHA) and dependent upon proximal femur size and geometry. Study objectives were to determine the variability of proximal femur size and geometry in primary cTHA patients and correlate them with patient demographics and body mass index (BMI).

Methods: Medical records of 127 consecutive primary cTHA patients were reviewed retrospectively. The demographic (ethnicity, sex, age) and BMI data were collected. Intertrochanteric (IT) distance, inner/outer proximal femur diameters and cortical thickness for the subtrochanteric (ST) and cortical diaphyseal (DP) regions were measured from anteroposterior radiographs. Descriptive statistics were used to correlate patient demographics and BMI with radiographic measurements.

Results: The study included 96 cTHA patients (mean age 60 years, range 22-91 years; 34 females; 72 Caucasian, 18 Black, and six Hispanic) with four underweight; 13 normal; 34 overweight, and 45 obese BMI. No correlation existed for patient age or race with radiographic measurements. Males had significantly larger proximal femur dimensions and cortical thickness than females. No BMI correlations existed for IT distance; BMI was directly proportional to outer diameter and cortical thickness in ST and DP regions, and inversely proportional to inner diameter in these regions.

Discussion: Greater proximal femur size appears to correlate with gender, but not with age or race. Larger subtrochanteric and diaphyseal outer diameters are significantly associated with higher BMI. A trend exists for larger subtrochanteric and diaphyseal inner diameters to be associated with lower BMI. These findings may have implications for optimal cTHA femoral component design.

\section{Keywords}

cementless total hip arthroplasty, proximal femur morphology, femoral stem, body mass index

\section{Open Peer Review \\ Approval Status ? 2 \\ version 1

$\checkmark$
view \\ 1. Loren Latta, University of Miami, Miami, USA \\ 2. Philip C Noble, Baylor College of Medicine, Houston, USA \\ Any reports and responses or comments on the article can be found at the end of the article.}


Corresponding author: Zbigniew Gugala (zgugala@utmb.edu)

Competing interests: The authors declared no competing interests.

Grant information: The author(s) declared that no grants were involved in supporting this work.

Copyright: ( 2015 Moulton DL et al. This is an open access article distributed under the terms of the Creative Commons Attribution License, which permits unrestricted use, distribution, and reproduction in any medium, provided the original work is properly cited. Data associated with the article are available under the terms of the Creative Commons Zero "No rights reserved" data waiver (CC0 1.0 Public domain dedication).

How to cite this article: Moulton DL, Lindsey RW and Gugala Z. Proximal Femur Size and Geometry in Cementless Total Hip Arthroplasty Patients [version 1; peer review: 1 approved, 1 approved with reservations] F1000Research 2015, 4:161

https://doi.org/10.12688/f1000research.6554.1

First published: 23 Jun 2015, 4:161 https://doi.org/10.12688/f1000research.6554.1 


\section{Introduction}

Cementless total hip arthroplasty (cTHA) is one of the most common orthopaedic procedures performed today. Much of its success is due to modern technological advances in implant design that permit cementless press-fit femoral component fixation ${ }^{1-18}$. Studies have shown that appropriate cementless femoral component size is critical for optimal implant initial stability, and maximizing femoral implant medullary canal fill enhances the endosteal contact between implant and bone to promote bone ingrowth, and therefore improved long-term outcome ${ }^{19-21}$.

Standard tapered cTHA stems typically rely on three-point fixation, which achieves more proximal load transfer and thereby decreases risk for stress shielding. Nonetheless, subsidence may occur owing to inadequate distal press-fit. More recent designs of anatomic stems aim to reproduce the normal contours of the intramedullary cavity to allow a more natural load distribution over the proximal femur without relying on a specific fixation point ${ }^{22}$. The clinical relevance of these evolving designs is the inhibition of aseptic loosening and stress shielding, and the optimization of implant longevity.

Because the quality of cementless femoral component press-fit is dependent upon matching the implant size to the dimensions and geometry of the proximal femur, determining the relationship between these parameters and basic patient characteristics such as age, race, gender, and body habitus may assist with operative planning. However, the priority of selecting the largest possible femoral stem size to achieve a tight fit often results in a substantial alteration of the implant's biomechanical properties. The bending stiffness of a cylindrical stem increases exponentially to the fourth power with increasing a stem diameter, and this phenomenon could be a specific concern in cTHA patients with a proximal femur size and geometry inversely related to their body mass, and when proximal femur size and geometry are incommensurate with body habitus, cTHA patients are potentially subjected to femoral implants that are too stiff or too flexible.

While several investigators have reported significant proximal femur anatomic variations in regard to patient gender, a correlation of body habitus with proximal femur size and geometry has not been reported. The objective of this study was to determine the variability of proximal femur size and geometry in primary cTHA patients, and determine its correlation with patient age, gender, ethnicity, and body habitus.

\section{Materials \& methods}

\section{Study patients}

One hundred twenty-seven patients with primary cTHAs performed at a single institution (University of Texas Medical Branch, Galveston, TX) from 2004 to 2008 were studied retrospectively. Inclusion criteria mandated that the patient was an adult who underwent elective unilateral total hip arthroplasty with a cementless femoral stem and had adequate postoperative radiographs of the involved hip and proximal femur. Exclusion criteria were patients with THAs that were bilateral, revisions, post-infection, acquired (post-traumatic) or due to congenital deformity of the proximal femur, or cemented THA. The study was conducted in compliance with the University of Texas Medical Branch policies and regulations regarding human subject research following study protocol review and approval by the Institutional Review Board (approval IRB \#08-156).

\section{Study variables}

Age, gender, ethnicity, and body mass index (BMI) at the time of surgery were documented for each cTHA patient. BMI was defined as the ratio of the patient's weight (kilograms) to the square of the height (meters). Patients were sub-categorized in accordance with their BMI as follows: underweight (BMI less than 18.5), normal weight (BMI between 18.5 and 24.9), overweight (BMI between 25 and 29.9), obese (BMI greater than 30).

The medullary canal size and cortex thickness of the proximal femur were determined by a series of measurements of the involved hip and proximal femur measured on a postoperative anteroposterior (AP) plain radiograph completed within two weeks of the surgery. The hip/proximal femur radiograph was performed using a standard technique with the $\mathrm{x}$-ray beam centered on the hip with neutral pelvic and lower extremity rotation. All study radiographs were accessed using the digital Picture Archiving and Communication System (IntelliSpace PACS; Philips, Andover, MA, USA) at our institution.

Proximal femur radiographic measurements included the intertrochanteric distance, the inner and outer femur cortical diameters of the femur at the subtrochanteric and diaphyseal regions, as well as the subtrochanteric and diaphyseal cortical thickness. The intertrochanteric distance (ITD) was measured from the tip of the greater trochanter to the tip of the lesser trochanter (Figure 1). The subtrochanteric inner cortical diameter (STID) and outer cortical diameter (STOD) were measured from just proximal to the distal inferior edge of the lesser trochanter perpendicular to the long axis of the diaphysis. The subtrochanteric cortical thickness (STCT) was calculated by subtracting the inner cortical diameter from the outer cortical diameter, and then dividing that figure in half (which assumes that the femur cross-section at that level is circular). The diaphyseal inner cortical diameter (DID), diaphyseal outer cortical diameter (DOD), and diaphyseal cortical thickness (DCT) were determined at a level of $4 \mathrm{~cm}$ proximal to the tip of the cementless femoral stem by using the same calculations used for the subtrochanteric region.

In order for these measurements to reflect the true dimensions of the osseous anatomy, a magnification factor was established for each radiograph. The magnification factor was determined by digitally measuring the outer diameter of the acetabular cup and comparing that measurement to the known outer diameter of the implant obtained from the operative report. This magnification calculation was used to adjust all radiographic measurements.

Proximal femur geometry was assessed using the intertrochantericto-subtrochanteric and subtrochanteric-to-diaphyseal ratios suggested in previous reports ${ }^{23,24}$ as a better measure of proximal femur morphology compared with individual anatomic dimensions. Also, mean total, cortical and medullary cross-sectional areas of subtrochanteric and diaphyseal regions were calculated and compared with patient gender and BMI. 


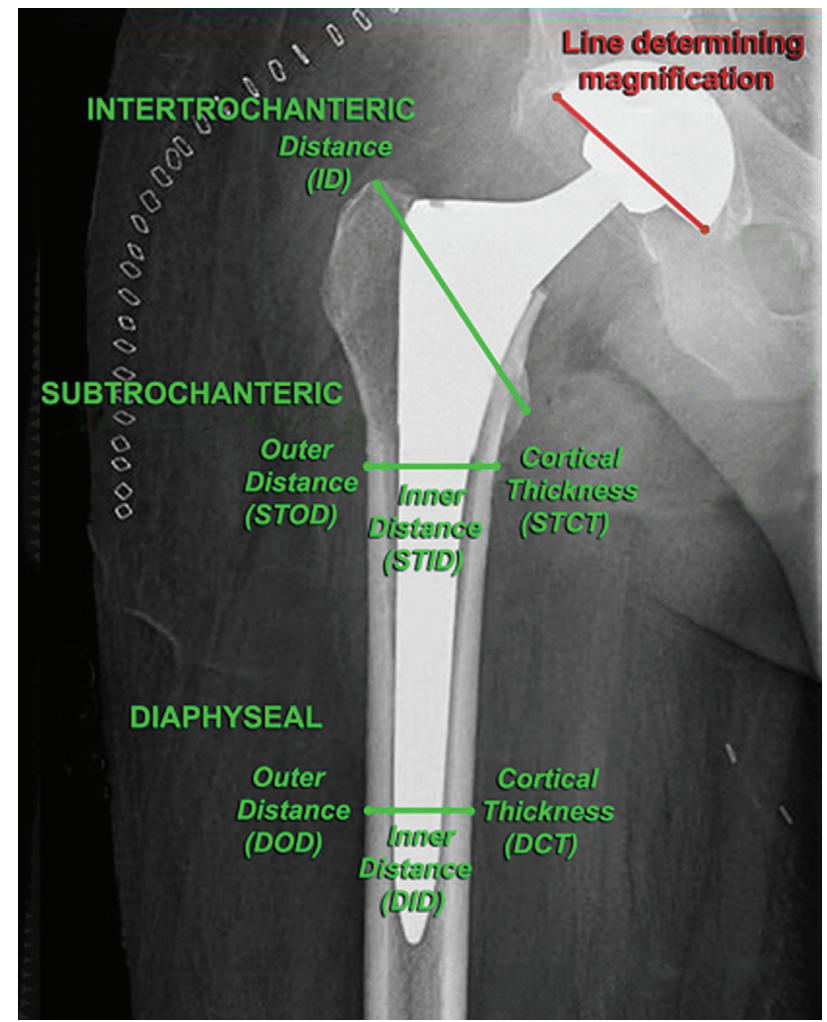

Figure 1. A postoperative anteroposterior (AP) plain radiograph of the hip region of a typical study patient with cementless total hip arthroplasty. Proximal femur size was established from measurements of intertrochanteric distance (ITD), outer and inner distance, and cortical thickness in the subtrochanteric region (STOD, STID, STCT, respectively), and the same in the diaphyseal region (DOD, DID, DCT, respectively) on AP plain radiographs. The intertrochanteric distance was measured between the tips of the greater and lesser trochanters; the subtrochanteric measurements were taken at the level immediately below the lesser trochanter, and the diaphyseal measurements were taken at the level of $4 \mathrm{~cm}$ above the tip of the cementless femoral stem. A magnification factor was established for each radiograph by measuring the outer diameter of the acetabular cup and comparing it to the known outer diameter of the implant obtained from the operative report, and all measurements were adjusted accordingly.

\section{Statistical methodology}

Descriptive statistics (SAS 9.3; SAS Institute Inc, Cary, NC, USA) were used to describe the sample characteristics and distribution of the proximal femur size and geometry (outcome variables). Pearson correlation test and ANOVA were used to test the bivariate association between outcome variable and sample characteristics (age, sex, race, and BMI) depending on the whether the sample characteristics variable was continuous or categorical. Multiple regression models were used to test the association between BMI and outcome variables, adjusting for age, sex, and race. The unadjusted and adjusted means of the outcome variables were also generated using regression models. A p-value threshold of less than 0.05 was considered statistically significant. Post hoc power analysis confirmed that the study sample size has sufficient power to detect a $20 \%$ difference in the designated parameters of the proximal femur morphology.

\section{Results}

The study consisted of 96 cTHA patients who met the inclusion/ exclusion criteria. The patients had the following demographic characteristics: mean age of 60.1 years ranging between 22 and 91 years, 34 patients were females (35.4\%) and 62 males (64.6\%); 72 patients were Caucasian (75\%), 18 Black (18.7\%), and 6 Hispanic $(6.3 \%)$ (Table 1). The BMI data included four $(4.2 \%)$ patients who were underweight $(\mathrm{BMI}<18.5) ; 13(13.5 \%)$ normal (BMI 18.5-24.9); 34 (35.4\%) overweight (BMI 25-29.9), and 45 $(46.9 \%)$ obese (BMI>30) (Figure 2). Proximal femur mean regional dimensions and standard deviations of the outcome variables for all patients in the study are depicted in Table 2.

Table 1. THA patient demographic and BMI characteristics.

\begin{tabular}{|l|c|}
\hline Patients & Mean (SD) or N (\%) \\
\hline Age & $60.1(14.1)$ \\
\hline Gender & \\
\hline \multicolumn{1}{|c|}{ Female } \\
\hline Male
\end{tabular}

$\$$ Mean (SD) for continuous variables and N (\%) for categorical variables

Table 2. Radiographic determination of proximal femur size.

\begin{tabular}{|c|c|}
\hline Measurement & Mean (SD) \\
\hline ITD & $74.4(6.8)$ \\
\hline STOD & $33.7(3.5)$ \\
\hline STID & $28.1(3.6)$ \\
\hline STCT & $5.6(1.1)$ \\
\hline DOD & $28.4(3.4)$ \\
\hline DID & $7.3(2.9)$ \\
\hline DCT & $11.1(2.9)$ \\
\hline
\end{tabular}

ITD, Intertrochanteric Distance; STOD/STID, Subtrochanteric Outer/Inner Distance; STCT, Subtrochanteric Cortical Thickness; DOD/ DID, Diaphyseal Outer/Inner Distance; DCT, Diaphyseal Cortical Thickness; SD, standard deviation. 
No significant correlation existed for patient age or race and all radiographic measurements (Table 3). Males had statistically significant larger proximal femur intertrochanteric $(\mathrm{p}<0.0001)$, subtrochanteric $(\mathrm{p}<0.008)$, and diaphyseal diameters $(\mathrm{p}<0.001)$ as well as cortical thickness compared to females $(\mathrm{p}=0.002)$. BMI was directly proportional to outer diameter and cortical thickness in both subtrochanteric and diaphyseal regions; however, BMI was inversely proportional to inner diameter in these same regions. BMI groups exhibited statistically significant correlation for measurements obtained for the subtrochanteric and diaphyseal, but not for the intertrochanteric region. Age and race were not significantly associated with any of the outcome variables (Table 4).

Increasing BMI was significantly associated with higher STOD, STCT, DOD, and DCT values $(\mathrm{P}=0.02,0.008,0.004$, and 0.0001 , respectively, in unadjusted tests). These significant associations persist after adjusting for age, sex and race (Table 5). Figure 3-Figure 5 graphically represent the associations between BMI and the outcome

\section{BMI Distribution among cTHA Patients}

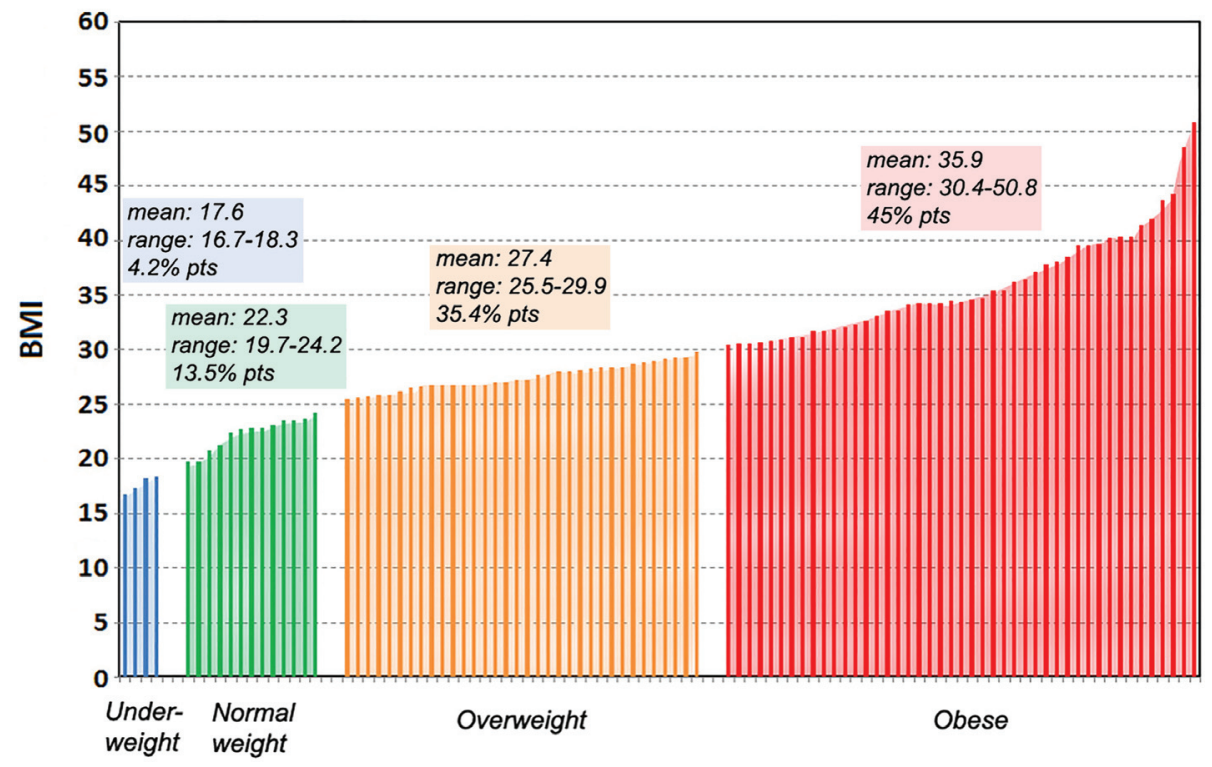

Figure 2. Body mass index (BMI) distribution among the studied cementless total hip arthroplasty patients (cTHA). Patients were categorized as underweight (BMI less than 18.5), normal weight (BMI between 18.5 and 24.9), overweight (BMI between 25 and 29.9 ), obese (BMl greater than 30).

Table 3. Bivariate association between age, gender, ethnicity and proximal femur measurements.

\begin{tabular}{|c|c|c|c|c|c|c|c|}
\hline & \multicolumn{7}{|c|}{ Mean (SD) } \\
\hline & ITD & STOD & STID & STCT & DOD & DID & DCT \\
\hline $\begin{array}{l}\text { Age } \\
P \text { value }\end{array}$ & $\begin{array}{r}-0.11 \\
0.22\end{array}$ & $\begin{array}{r}-0.04 \\
0.69\end{array}$ & $\begin{array}{l}0.06 \\
0.53\end{array}$ & $\begin{array}{r}-0.15 \\
0.10\end{array}$ & $\begin{array}{r}-0.04 \\
0.67\end{array}$ & $\begin{array}{l}0.06 \\
0.48\end{array}$ & $\begin{array}{r}-0.10 \\
0.25\end{array}$ \\
\hline \multicolumn{8}{|l|}{ Gender } \\
\hline Female & $68.9(5.6)$ & $31.5(3.4)$ & $21.4(3.4)$ & $5.1(1.0)$ & $25.8(2.8)$ & $11.6(2.8)$ & $7.1(1.4)$ \\
\hline Male & $77.0(5.7)$ & $34.9(3.0)$ & 23.2 (3.6) & $5.8(1.1)$ & 29.7 (2.9) & $13.2(2.8)$ & $8.3(1.4)$ \\
\hline$P$ value & $<0.0001$ & $<0.0001$ & 0.008 & 0.0002 & $<0.0001$ & 0.004 & $<0.0001$ \\
\hline \multicolumn{8}{|l|}{ Ethnicity } \\
\hline Caucasian & $74.7(6.7)$ & 34.1 (3.6) & $22.9(3.5)$ & $5.6(1.1)$ & $28.5(3.5)$ & $12.6(2.7)$ & $8.0(1.6)$ \\
\hline Black & $73.7(7.5)$ & $33.2(3.0)$ & $21.4(3.5)$ & $5.9(1.1)$ & $28.4(3.5)$ & $12.9(3.6)$ & $7.7(1.2)$ \\
\hline Hispanics & $72.5(6.8)$ & $33.0(3.3)$ & $22.8(4.7)$ & $5.1(1.1)$ & $27.9(2.4)$ & $12.9(2.5)$ & $7.5(1.3)$ \\
\hline$P$ value & 0.55 & 0.42 & 0.159 & 0.18 & 0.85 & 0.89 & 0.56 \\
\hline
\end{tabular}


Table 4. Unadjusted and adjusted mean proximal femur measurements versus BMI groups.

\begin{tabular}{|c|c|c|c|c|c|c|}
\hline \multirow{2}{*}{\multicolumn{2}{|c|}{ Measurement }} & \multicolumn{4}{|c|}{ Mean (SE) } & \multirow{3}{*}{$\begin{array}{r}\text { P value } \\
0.41\end{array}$} \\
\hline & & \multirow{2}{*}{$\begin{array}{c}\text { Underweight } \\
70.6(3.4)\end{array}$} & \multirow{2}{*}{$\begin{array}{c}\text { Normal } \\
72.7(1.5)\end{array}$} & \multirow{2}{*}{$\begin{array}{c}\text { Overweight } \\
75.0(1.0)\end{array}$} & \multirow{2}{*}{$\begin{array}{c}\text { Obese } \\
75.0(0.9)\end{array}$} & \\
\hline ITD & Unadjusted & & & & & \\
\hline & Adjusted $^{\$}$ & $69.4(2.9)$ & $69.8(1.4)$ & 72.7 (1.0) & $72.0(0.9)$ & 0.22 \\
\hline \multirow[t]{2}{*}{ STOD } & Unadjusted & $30.0(1.7)$ & $33.3(0.8)$ & $33.3(0.5)$ & $34.7(0.5)$ & 0.02 \\
\hline & Adjusted $^{\$}$ & $29.2(1.6)$ & $32.1(0.8)$ & $32.2(0.5)$ & $33.6(0.5)$ & $<0.0001$ \\
\hline \multirow[t]{2}{*}{ STID } & Unadjusted & $21.1(1.8)$ & $22.9(0.8)$ & $22.3(0.5)$ & $22.9(0.5)$ & 0.69 \\
\hline & Adjusted $\$$ & 20.5 (1.8) & $22.4(0.9)$ & $21.8(0.6)$ & $22.3(0.6)$ & 0.05 \\
\hline \multirow[t]{2}{*}{ STCT } & Unadjusted & $4.5(0.5)$ & $5.2(0.2)$ & $5.5(0.2)$ & $5.9(0.1)$ & 0.008 \\
\hline & Adjusted $\$$ & $4.3(0.5)$ & $4.9(0.3)$ & $5.2(0.2)$ & $5.6(0.2)$ & $<0.0001$ \\
\hline \multirow[t]{2}{*}{ DOD } & Unadjusted & $24.5(1.6)$ & $27.8(0.7)$ & $27.9(0.5)$ & $29.5(0.4)$ & 0.004 \\
\hline & Adjusted $\$$ & $23.7(1.4)$ & $26.8(0.7)$ & $26.9(0.5)$ & $28.5(0.5)$ & $<0.0001$ \\
\hline \multirow[t]{2}{*}{ DID } & Unadjusted & $13.1(1.5)$ & $13.1(0.6)$ & $12.6(0.4)$ & $12.6(0.4)$ & 0.92 \\
\hline & Adjusted $^{\$}$ & $12.8(1.5)$ & $13.1(0.7)$ & $12.5(0.5)$ & $12.5(0.5)$ & 0.10 \\
\hline \multirow[t]{2}{*}{ DCT } & Unadjusted & $5.7(0.7)$ & $7.4(0.3)$ & $7.6(0.2)$ & $8.4(0.2)$ & 0.0001 \\
\hline & Adjusted $^{\$}$ & $5.4(0.7)$ & $6.8(0.3)$ & $7.2(0.2)$ & $8.0(0.2)$ & $<0.0001$ \\
\hline
\end{tabular}

${ }^{\$}$ Adjusted for age, gender and ethnicity using multiple regression analysis

Table 5. Association between BMI and proximal femur measurements (BMI as a continuous variable)*.

\begin{tabular}{|c|c|c|c|c|c|c|c|}
\hline \multirow{2}{*}{ BMI } & \multicolumn{7}{|c|}{$\begin{array}{l}\text { Regression Coefficient (SE) } \\
\text { (P value) }\end{array}$} \\
\hline & ITD & STOD & STID & STCT & DOD & DID & DCT \\
\hline Unadjusted & $\begin{array}{c}0.05(0.09) \\
(P=0.59)\end{array}$ & $\begin{array}{c}0.12(0.05) \\
(P=0.02)\end{array}$ & $\begin{array}{l}0.03(0.05) \\
(P=0.55)\end{array}$ & $\begin{array}{l}0.04(0.02) \\
(P=0.005)\end{array}$ & $\begin{array}{l}0.14(0.04) \\
(P=0.002)\end{array}$ & $\begin{array}{l}0.01(0.04) \\
(P=0.85)\end{array}$ & $\begin{array}{l}0.07(0.02) \\
(P=0.001)\end{array}$ \\
\hline Adjusted & $\begin{array}{l}0.05(0.08) \\
(P=0.48)\end{array}$ & $\begin{array}{l}0.12(0.04) \\
(P=0.004)\end{array}$ & $\begin{array}{l}0.03(0.05) \\
(P=0.48)\end{array}$ & $\begin{array}{l}0.04(0.01) \\
(P=0.003)\end{array}$ & $\begin{array}{l}0.15(0.04) \\
(P=0.0001)\end{array}$ & $\begin{array}{l}0.01(0.04) \\
(P=0.80)\end{array}$ & $\begin{array}{l}0.07(0.02) \\
(P=0.0004)\end{array}$ \\
\hline
\end{tabular}

${ }^{*}$ Adjusted for age, gender, and ethnicity

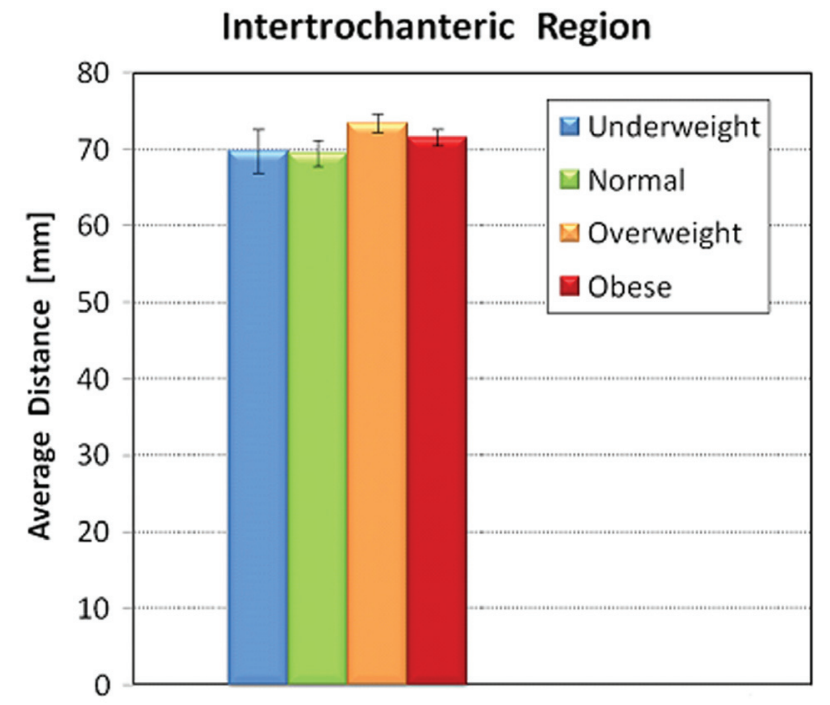

Figure 3. The average intertrochanteric distance according to BMI of cementless arthroplasty patients. Error bars represent standard deviation. 


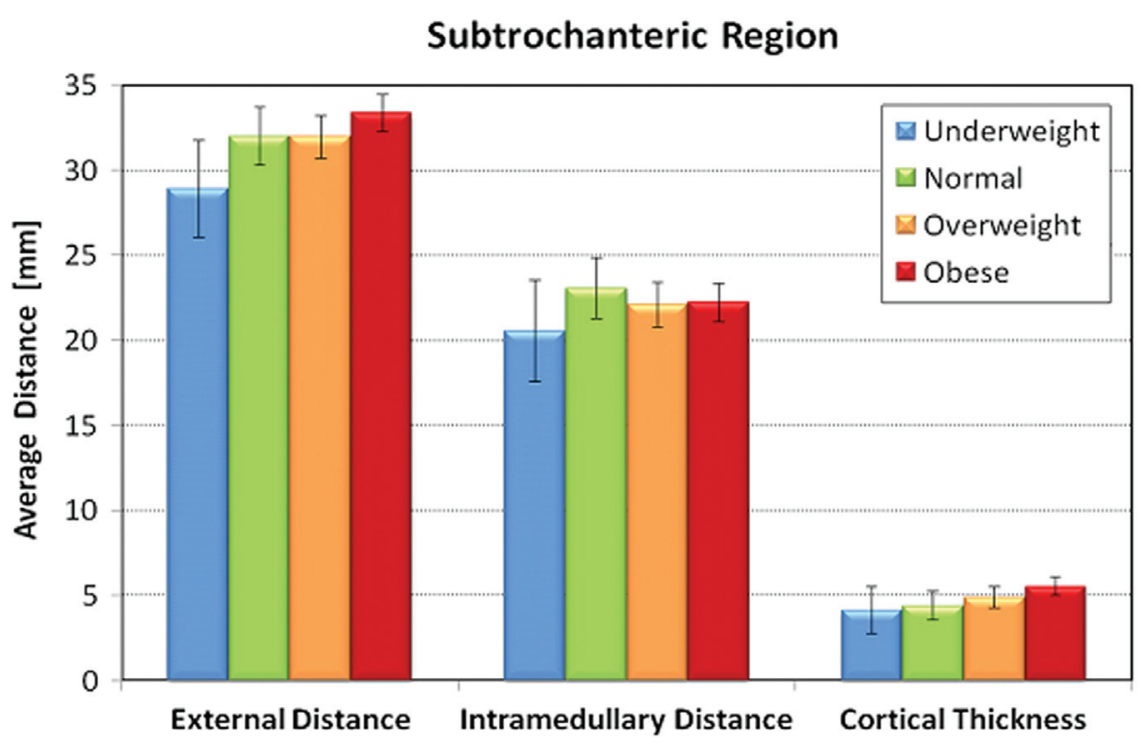

Figure 4. The measurements in the subtrochanteric region of the femur according to BMI of cementless arthroplasty patients. Error bars represent standard deviation.

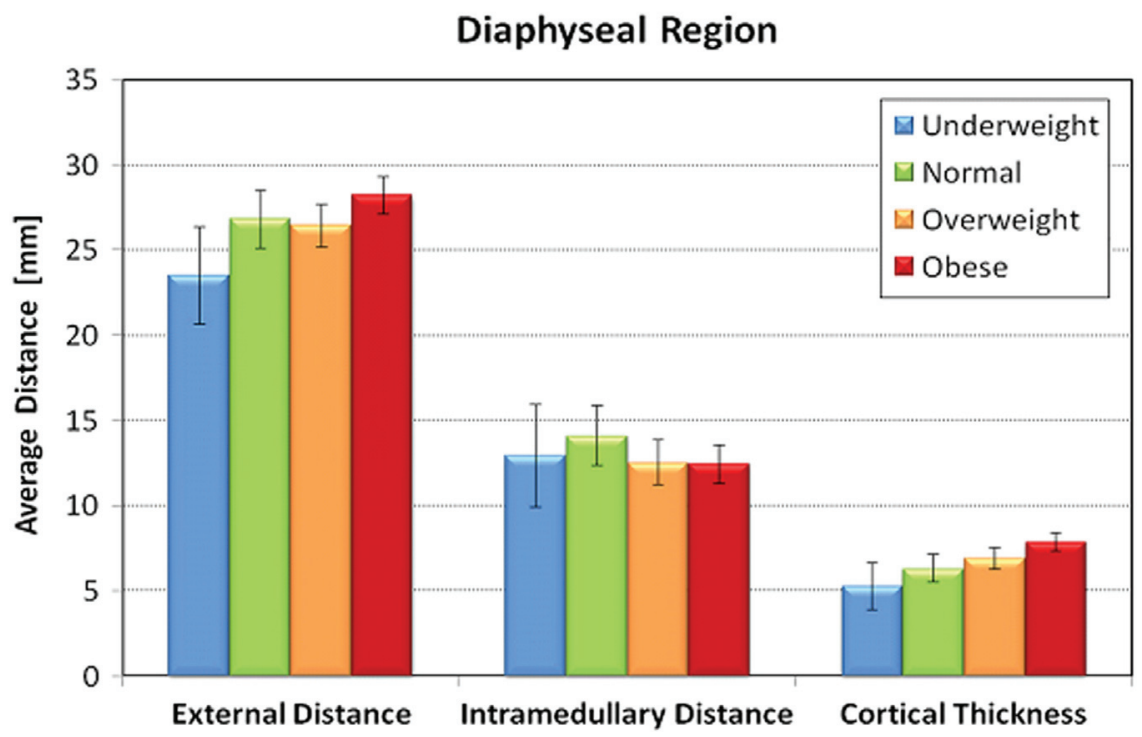

Figure 5. The measurements in the diaphyseal region of the femur according to BMI of cementless arthroplasty patients. Error bars represent standard deviation.

variables. Table 6 demonstrates a significant linear trend between BMI and STOD, STCT, DOD and DCT. No significant correlation was detected between BMI and intertrochanteric distance, subtrochanteric inner diameter, or diaphyseal inner diameter.

The proximal femur geometry assessed form determining the intertrochanteric-to-subtrochanteric and subtrochanteric-to-diaphyseal did not demonstrate a statistically-significant association with patient gender (Table 6). The mean cross-sectional areas of subtrochanteric and diaphyseal regions versus gender and BMI group are depicted
Table 6. Mean geometric measurement ratios of intertrochanteric, subtrochanteric, and diaphyseal regions versus gender.

\begin{tabular}{|l|c|c|}
\hline & ITD/STID & STID/DID \\
\hline Female & $3.3(0.6)$ & $1.9(0.4)$ \\
\hline Male & $3.4(0.6)$ & $1.8(0.3)$ \\
\hline (P value) & $(0.35)$ & $(0.14)$ \\
\hline
\end{tabular}


in Table 7 and Table 8, respectively. No statistical significant associations were observed between these parameters of the proximal femur geometry and patient gender. The normal-weight group had the largest average canal width and on average received the largest femoral stems, whereas the overweight and obese patients had smaller canals, and received smaller femoral components (Table 8).

Table 7. Mean cross-sectional areas of subtrochanteric and diaphyseal regions versus gender.

\begin{tabular}{|c|c|c|c|c|c|c|}
\hline & \multicolumn{3}{|c|}{ Subtrochanteric Region } & \multicolumn{3}{|c|}{ Diaphyseal Region } \\
\hline & $\begin{array}{l}\text { Total } \\
\text { Area } \\
\left(\mathrm{cm}^{2}\right)\end{array}$ & $\begin{array}{c}\text { Cortical } \\
\text { Area } \\
\left(\mathrm{cm}^{2}\right)\end{array}$ & $\begin{array}{c}\text { Medullary } \\
\text { Area } \\
\left(\mathrm{cm}^{2}\right)\end{array}$ & $\begin{array}{l}\text { Total } \\
\text { Area } \\
\left(\mathrm{cm}^{2}\right)\end{array}$ & $\begin{array}{c}\text { Cortical } \\
\text { Area } \\
\left(\mathbf{c m}^{2}\right)\end{array}$ & $\begin{array}{c}\text { Medullary } \\
\text { Area } \\
\left(\mathrm{cm}^{2}\right)\end{array}$ \\
\hline Female & 7.9 & $\begin{array}{c}4.2 \\
\left(54 \%^{\$}\right)\end{array}$ & $\begin{array}{c}3.7 \\
(46 \%)\end{array}$ & 5.3 & $\begin{array}{c}4.2 \\
\left(79 \%^{\$}\right)\end{array}$ & $\begin{array}{c}1.1 \\
\left(21 \%^{\$}\right)\end{array}$ \\
\hline Male & 9.6 & $\begin{array}{c}5.3 \\
\left(56 \%^{\$}\right)\end{array}$ & $\begin{array}{c}4.3 \\
\left(44 \%^{\$}\right)\end{array}$ & 7.0 & $\begin{array}{c}5.6 \\
\left(80 \%^{\$}\right)\end{array}$ & $\begin{array}{c}1.4 \\
\left(20 \%{ }^{\$}\right)\end{array}$ \\
\hline$P$ value & & 0.25 & & & 0.62 & \\
\hline
\end{tabular}

Table 8. Average implanted stem crosssectional diameter versus BMI.

\begin{tabular}{|c|c|c|}
\hline & Proximal area & Distal area \\
\hline BMI group & & \\
\hline Underweight & 441 & 85 \\
\hline Normal & 588 & 147 \\
\hline Overweight & 518 & 114 \\
\hline Obese & 543 & 128 \\
\hline
\end{tabular}

Dataset 1. Raw data for 'Proximal femur size and geometry in cementless total hip arthroplasty patients'

http://dx.doi.org/10.5256/f1000research.6554.d49796

The study raw data were collected following a retrospective review of medical records and postoperative imaging of patients who underwent cementless total hip arthroplasty in our institution and met the study inclusion and exclusion criteria. The raw data were subsequently reviewed and refined for consistency and completeness prior to statistical analysis ${ }^{50}$.

\section{Discussion}

Several cTHA studies have emphasized the importance of femoral fit in achieving primary implant stability, reducing early prosthetic loosening, and encouraging bony ingrowth ${ }^{2-9}$. Understanding the bony anatomy of the proximal femur is a prerequisite for optimizing femoral implant press-fit and determining the impact of factors such as ethnicity, gender, age, and body habitus ${ }^{10,12}$. At present, clinical priority is given to selecting the largest possible femoral stem to accomplish a tight fit, despite increased implant size association with a considerable change in the stem biomechanical properties (four-power increase in bending stiffness in relation to stem diameter). Hence, the size and geometry of the proximal femur may have significant implications for the cementless femoral stem biomechanical characteristics, especially in patients for whom a large discrepancy exists between their proximal femur dimensions and their body habitus.

Previous anthropometric studies have compared the variability of femoral bony architecture among different races. Travison et al. ${ }^{25}$ used bone densitometry to show that African-Americans have larger intertrochanteric and diaphyseal outer diameters compared to Hispanics and Caucasians. Marshall et al. ${ }^{26}$ determined that African-Americans and Asian men have greater femoral neck and shaft mean cortical thickness compared to Caucasian men. Other studies $^{27,28}$ demonstrated that African-American women had a larger cross-sectional area, larger outer diameter, smaller inner diameter, and thicker cortices in the femoral neck and shaft compared to Caucasian women, and also have smaller inner and outer diameters, but thicker cortices in the intertrochanteric region. This is in contrast with the results of the present study, which did not establish a statistically significant correlation between race and the proximal dimensions. These findings corroborate those of Peacock et al. ${ }^{29}$ and Saeed $e t a l .{ }^{30}$, who reported computed tomography measurements of the proximal femur to be independent of race for both sexes. These studies, however, have substantiated significant differences in bone mineral density among these ethnic groups ${ }^{25,26,29,31}$.

The literature has shown that men generally have a larger bony architecture compared to women, even when adjusted for confounding variables ${ }^{29,32,33}$. These differences have promoted the development of gender-specific arthroplasty implant designs. Kostamo et $a l .{ }^{34}$ in a large primary THA cohort demonstrated that differences in clinical outcome scores were found only in the WOMAC pain score in favor of the female cohort (39.4 versus 36.1 ), whereas the survivorship and revision rate were not significantly different. Men required larger femoral stems with greater stem lengths, neck offset, and neck lengths. Despite the gender variations in proximal femur anatomy, the authors concluded that current implant systems in their versatility sufficiently address the different size and offset needs of both male and female patients. Similar results have been reported for gender-specific total knee arthroplasty components ${ }^{35}$.

In the present study a statistically significant difference in BMI was determined between males and females for all outcome variables (Table 4). The proximal femur morphology assessment involving ratios of geometric measures as opposed to individual anatomic dimensions demonstrated that, although the single measures of the specific proximal femur regions exhibited statistically significant differences (Table 2), the intertrochanteric-to-subtrochanteric and subtrochanteric-to-diaphyseal ratios did not (Table 6 and Table 7). These findings suggest that although the bony anatomy of men is larger than that of women, the proportional increase in proximal femur size, and subsequent shape, is similar for both. Also, the cortical and medullary cross-sectional areas as a percentage of the total cross-sectional area in the subtrochanteric and diaphyseal regions were similar for both men and women (Table 8). Lamellar bone stiffness is largely determined by its radius and cortical content. 
Therefore, although women may exhibit less lamellar bone stiffness, this difference is in proportion to that of men. Furthermore, a disparity did not exist between anatomic regions for either sex, and this may suggest that although men may require larger femoral implants compared to women, gender-specific implant geometry may not be necessary as the proximal femur regional anatomic proportions are equivalent.

Bone mass decreases with age after its peak in the third decade of life; however, studies have shown that the outer diameter of bone slightly increases with age, possibly owing to continued periosteal appositional growth ${ }^{25,33,36,37}$. But to produce an age-associated decrease in bone density while its outer diameter is increasing would require thinning of the cortex. Our study did not demonstrate a statistically significant correlation between age and proximal femur geometry, although the aforementioned trends may be seen (Figure 6 and Figure 7). Bone adaptation to mechanical loading (Wolff's law) is site specific because of the unique magnitude, direction, and type of load in each anatomic region. Among the major determinants of the loads experienced at the hip joint

Subtrochanteric Measurements vs. Age

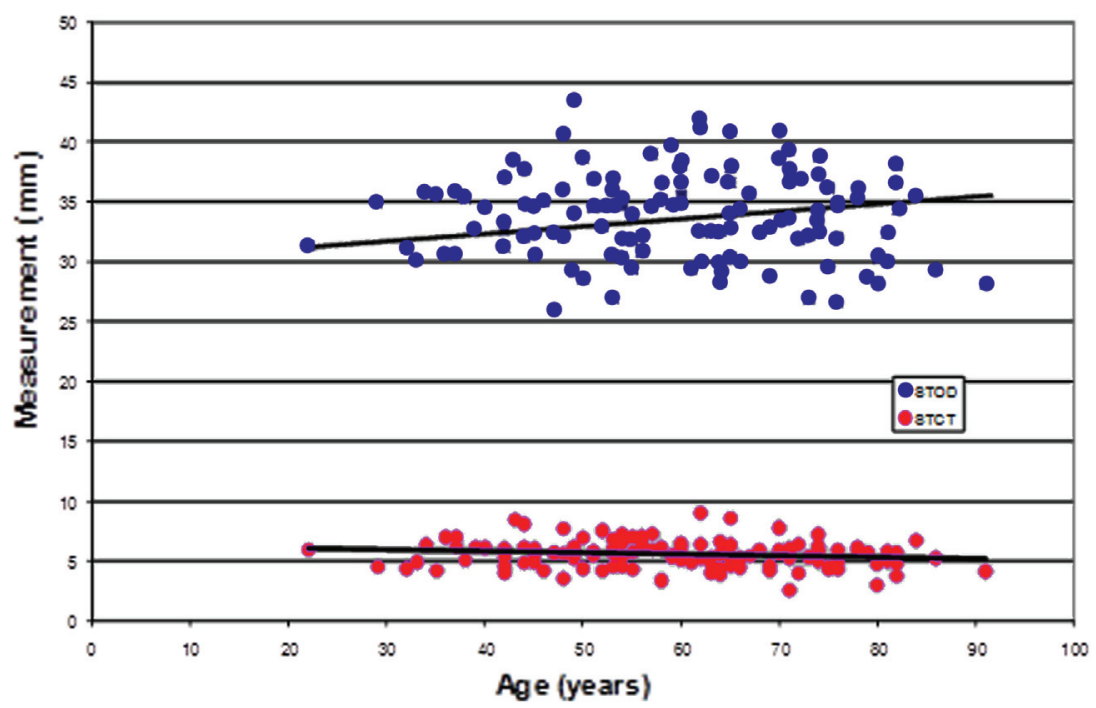

Figure 6. The subtrochanteric measurements according to age of cementless hip arthroplasty patients (STOD, subtrochanteric outer distance; STCT, subtrochanteric cortical thickness).

Diaphyseal Measurements vs. Age

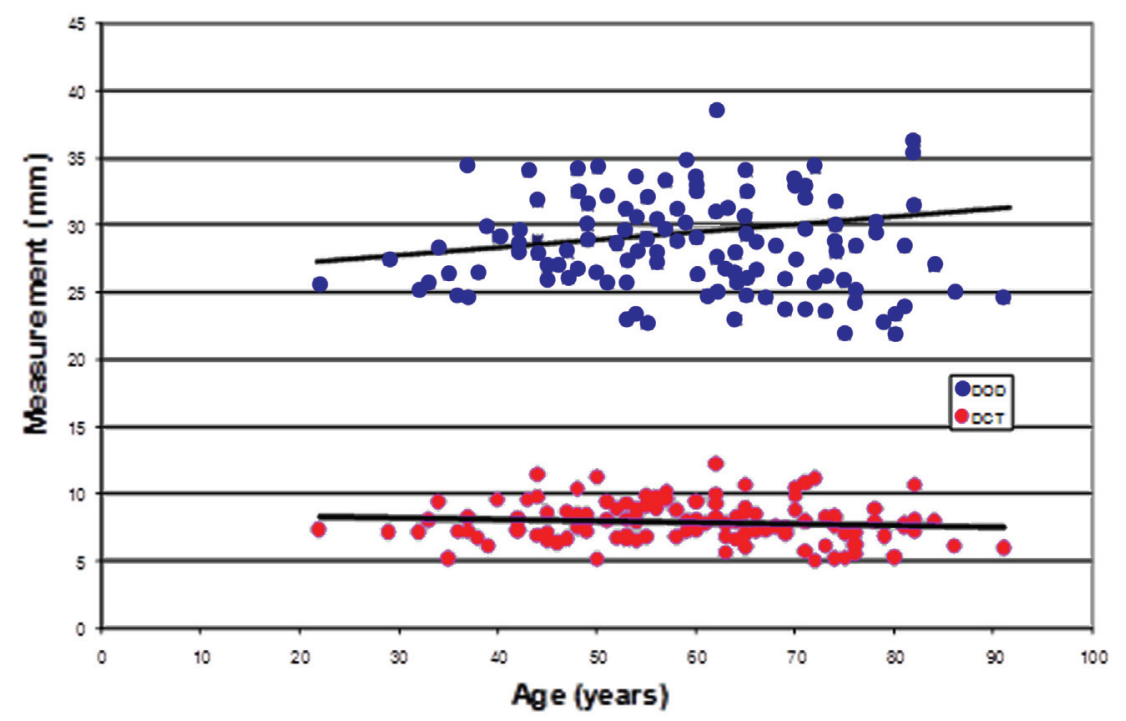

Figure 7. The diaphyseal measurements according to age of cementless hip arthroplasty patients (DOD, diaphyseal outer distance; DCT, diaphyseal cortical thickness). 
and subtrochanteric region of the femur is body weight. In a bone densitometry study, Petit et al $^{38,39}$ demonstrated that the femoral neck and shaft in children and adolescents who were overweight due to a higher percentage of lean body mass had larger diameters, cross-sectional areas, and cortical thicknesses compared to normalweight individuals. Van der Meulen et al $^{40}$ indicated that of age, pubertal stage, body mass, and height, body mass is a stronger predictor of femoral cross-sectional properties than age, pubertal stage, or height. Moreover, these authors concluded that the correlation of body mass with femoral cross-sectional structure is independent of gender. Interestingly, other authors have indicated that body weight and femoral dimensions may possess common genetic factors ${ }^{41-43}$.

In our study, there were significant differences in subtrochanteric (STOD, STCT) and diaphyseal (DOD and DCT) measurements versus individual BMI groups (Table 4), and versus BMI as a continuous variable (Table 5). This correlation demonstrated the significant linear trends between STOD, STCT, DOD and DCT and BMI. The subtrochanteric inner diameter (STID) versus BMI groups demonstrated statistical significance only after being adjusted for age, sex, and race; the same was observed for the diaphyseal inner diameter region (Table 5). In both regions, the outer diameters increased with larger BMI, but the cortical thickness also increased, resulting in fairly consistent inner diameters among BMI groups. On the other hand, the differences in intertrochanteric measurement (ITD) were not statistically significant. Intertrochanteric distance can be highly variable on anterior-posterior plain radiography with varying degrees of hip rotation. Although AP hip radiographs in our institution are routinely attempted with the femur in neutral alignment, many patients with longstanding hip disease may have had contractures causing external proximal femur rotation. Our study showed a less than $5 \%$ variation in the ITD measurements.

One concern with press-fit femoral components is the disparity that frequently exists between the anatomy/configuration of the human proximal femur and the specific design and size limitations of any implant system. Our study confirms that a wide variation exists in proximal femur geometry among hip arthroplasty patients. The notion that current off-the-shelf femoral components do not accurately accommodate this wide variation is supported by reports of persistent bone stress shielding or implant subsidence despite advances in stem design. All cTHA study patients received a tapered stem, and the average proximal and distal cross-sectional area of the implanted femoral component according to BMI group is depicted in Table 8. The normal-weight group had the largest average canal width and, on average, received the largest femoral stems. By comparison, overweight and obese patients had smaller canals, and received smaller femoral components. These findings suggest that the normal-weight patients may receive implants which for their body habitus, are excessively stiff; conversely, obese patients may actually be receiving implants that are not stiff enough. Although, to our knowledge, there has not been a study that relates implant stiffness and fatigue resistance to implant longevity among different BMI groups, several studies suggest no differences in the clinical or radiographic outcomes among different BMI groups ${ }^{44,45}$.

A correlation of body weight with the incidence or severity of thigh pain has not been demonstrated. Several studies have also attempted to correlate thigh pain with stem size; however, their results have been inconclusive ${ }^{7,46}$. Stem size and/or geometry clearly influences thigh pain, as a stem with a better fit will result in more stability and bony ingrowth, and theoretically, less thigh pain ${ }^{47,48}$. Similarly, stem stiffness may influence thigh pain as a stem with a stiffness closer to that of the host femur would result in more uniform stress transfer ${ }^{48,49}$. Body weight could also have a great influence on the incidence of thigh pain, especially if there is a considerable mismatch of host bone to implant stiffness. In the present study, normalweight patients had smaller outer diameters with thinner cortices compared to obese patients, but actually received larger implants owing to their larger canals. Theoretically, this mismatch in stiffness may the cause of thigh pain in normal-weight individuals, however, this has not been proven clinically ${ }^{44}$.

The present study has several limitations. Selection bias may have been introduced into the study - the typical study patients were older and obese, while younger, underweight or normal-weight patients were underrepresented. The study demographic data may also be inconsistent or incomplete regarding ethnicity and body mass. The designation of ethnicity was used as recorded in the medical records without a standard definition or verification. Also, the study design did not account for physical activity, or the lack thereof, as well as any differences between low and high body mass as previously discussed. In addition, each patient underwent cTHA with a press-fit femoral component, and the amount of endosteal cortical bone removed through reaming and/or broaching was undetermined. Finally, the complexity of the proximal femur geometry was assessed only with plain radiography.

In summary, the present study shows a strong correlation between the proximal femur dimension and gender, but not with age or ethnicity. This correlation is statistically significant for outer diameter and cortical thickness in both the subtrochanteric and diaphyseal regions of the proximal femur. Conversely, there is a non statistically significant reverse trend between BMI and inner medullary diameter in both regions. The study findings suggest that genderspecific femoral implants based on presumed differences between male and female proximal femur size but not geometry may be warranted. The development of cTHA femoral components that more accurately address the proximal femur variations specifically reflected by the patient overall and local biomechanical demands (BMI, bone quality, etc.) may have considerable merit in extending implant longevity.

\section{Conclusions}

The present study demonstrates a strong correlation between gender and the size of the proximal femur, but no correlation with age or race. There is a direct correlation between BMI and proximal femur size; this correlation is statistically significant for outer diameter and cortical thickness in both the subtrochanteric and diaphyseal regions. Conversely, there is a non statistically significant reverse trend between BMI and inner medullary diameter in both regions.

Study results suggest that gender-specific cTHA femoral component matching male versus female proximal femur size may be indicated, and the development of femoral stems that addresses the 
proximal femur anatomic variations together with its matched biomechanical properties may have considerable merit.

\section{Data availability}

F1000Research: Dataset 1. Raw data for 'Proximal femur size and geometry in cementless total hip arthroplasty patients', 10.5256/ f1000research.6554.d49796 $6^{50}$

\section{Author contributions}

DLM - data collection, data analysis, manuscript preparation; RWL study design, manuscript preparation; ZG - study design, data analysis, manuscript preparation. All authors have seen and agreed to the final content of the manuscript.

\section{Competing interests}

The authors declared no competing interests.

\section{Grant information}

The authors declared that no grants were involved in supporting this work.

\section{Acknowledgements}

We thank Alai Tan, $\mathrm{PhD}$, for assistance in statistical analysis and Suzanne Simpson, BA, for editing the manuscript.
1. Bourne R, Mukhi S, Zhu N, et al.: Role of obesity on the risk for total hip or knee arthroplasty. Clin Orthop Relat Res. 2007; 465: 185-8. PubMed Abstract

2. Burke DW, O'Connor DO, Zalenski EB, et al:: Micromotion of cemented and uncemented femoral components. J Bone Joint Surg Br. 1991; 73(1): 33-7. PubMed Abstract

3. Callaghan JJ, Fulghum CS, Glisson RR, et al.: The effect of femoral stem geometry on interface motion in uncemented porous-coated total hip prostheses. Comparison of straight-stem and curved-stem designs. J Bone Joint Surg Am. 1992; 74(6): 839-48. PubMed Abstract

4. Christie M, Brinson MF: Proximal/distal mismatch: type $\mathbf{A}$ and $\mathbf{C}$ femurs. Orthopedics. 2005; 28(9 Suppl): s1033-6. PubMed Abstract

5. Effenberger H, Graf R, May M, et al.: Anatomically adapted, HA coated SBG stem--ten years of successful implantation. Biomed Tech (Berl). 2004; 49(10): 290-4. PubMed Abstract | Publisher Full Text

6. Engh CA Jr, Mohan V, Nagowski JP, et al.: Influence of stem size on clinical outcome of primary total hip arthroplasty with cementless extensively porouscoated femoral components. J Arthroplasty. 2009; 24(4): 554-9. PubMed Abstract | Publisher Full Text

7. Haraguchi K, Sugano N, Nishii T, et al:: Comparison of fit and fill between anatomic stem and straight tapered stem using virtual implantation on the ORTHODOC workstation. Comput Aided Surg. 2001; 6(5): 290-6. PubMed Abstract

8. Helm CS, Greenwald AS: The rationale and performance of modularity in total hip arthroplasty. Orthopedics. 2005; 28(9 Suppl): s1113-5. PubMed Abstract

9. Howard JL, Hui AJ, Bourne RB, et al:: A quantitative analysis of bone support comparing cementless tapered and distal fixation total hip replacements. J Arthroplasty. 2004; 19(3): 266-73. PubMed Abstract | Publisher Full Text

10. Husmann O, Rubin PJ, Leyvraz PF, et al:: Three-dimensional morphology of the proximal femur. J Arthroplasty. 1997; 12(4): 444-50. PubMed Abstract | Publisher Full Text

11. Kim YH, Kim VE: Cementless porous-coated anatomic medullary locking total hip prostheses. J Arthroplasty. 1994; 9(3): 243-52. PubMed Abstract | Publisher Full Text

12. Laine HJ, Lehto MU, Moilanen T: Diversity of proximal femoral medullary canal. J Arthroplasty. 2000; 15(1): 86-92. PubMed Abstract | Publisher Full Text

13. Laine HJ, Puolakka TJ, Moilanen T, et al.: The effects of cementless femoral stem shape and proximal surface texture on 'fit-and-fill' characteristics and on bone remodeling. Int Orthop. 2000; 24(4): 184-90. PubMed Abstract | Publisher Full Text | Free Full Text

14. Malchau H, Wang YX, Kärrholm J, et al.: Scandinavian multicenter porous coated anatomic total hip arthroplasty study. Clinical and radiographic results with 7- to 10-year follow-up evaluation. J Arthroplasty. 1997; 12(2): 133-48. PubMed Abstract | Publisher Full Text

15. Nishihara S, Sugano N, Nishii T, et al.: Comparison of the fit and fill between the Anatomic Hip femoral component and the VerSys Taper femoral componen using virtual implantation on the ORTHODOC workstation. J Orthop Sci. 2003; 8(3): 352-60.

PubMed Abstract | Publisher Full Text

16. Noble PC, Alexander JW, Lindahl LJ, et al:: The anatomic basis of femoral component design. Clin Orthop Relat Res. 1988; 235: 148-65. PubMed Abstract

17. Van der Wal BC, de Kramer BJ, Grimm B, et al. Femoral fit in ABG-Il hip stems, influence on clinical outcome and bone remodeling: a radiographic study. Arch Orthop Trauma Surg. 2008; 128(10): 1065-72. PubMed Abstract | Publisher Full Text

18. Viceconti M, Pancanti A, Dotti M, et al.: Effect of the initial implant fitting on the predicted secondary stability of a cementless stem. Med Biol Eng Comput. 2004; 42(2): 222-9.

PubMed Abstract | Publisher Full Text

19. Engh CA Jr, Culpepper WJ 2nd, Engh CA: Long-term results of use of the anatomic medullary locking prosthesis in total hip arthroplasty. $J$ Bone Joint Surg Am. 1997; 79(2): 177-84. PubMed Abstract

20. Cameron HU, Pilliar RM, MacNab I: The effect of movement on the bonding of porous metal to bone. J Biomed Mater Res. 1973; 7(4): 301-11. PubMed Abstract | Publisher Full Text

21. Panisello JJ, Herrero L, Canales $\mathrm{V}$, et al.: Long-term remodeling in proximal femur around a hydroxyapatite-coated anatomic stem: ten years densitometric follow-up. J Arthroplasty. 2009; 24(1): 56-64. PubMed Abstract | Publisher Full Tex

22. Østbyhaug $\mathrm{PO}$, Klaksvik J, Romundstad $\mathrm{P}$, et al.: An in vitro study of the strain distribution in human femora with anatomical and customised femoral stems. J Bone Joint Surg Br. 2009; 91(5): 676-82. PubMed Abstract | Publisher Full Text

23. Gregory JS, Testi D, Stewart A, et al:: A method for assessment of the shape of the proximal femur and its relationship to osteoporotic hip fracture. Osteoporos Int. 2004; 15(1): 5-11. PubMed Abstract | Publisher Full Text

24. O'Neill TW, Grazio S, Spector TD, et al:: Geometric measurements of the proximal femur in UK women: secular increase between the late 1950s and early 1990s. Osteoporos Int. 1996; 6(2): 136-40. PubMed Abstract | Publisher Full Text

25. Travison TG, Beck TJ, Esche GR, et al:: Age trends in proximal femur geometry in men: variation by race and ethnicity. Osteoporos Int. 2008; 19(3): 277-87. PubMed Abstract | Publisher Full Text

26. Marshall LM, Zmuda JM, Chan BK, et al:: Race and ethnic variation in proximal femur structure and BMD among older men. J Bone Miner Res. 2008; 23(1): 121-30. PubMed Abstract | Publisher Full Text | Free Full Text

27. Nelson DA, Barondess DA, Hendrix SL, et al:: Cross-sectional geometry, bone strength, and bone mass in the proximal femur in black and white postmenopausal women. J Bone Miner Res. 2000; 15(10): 1992-97. PubMed Abstract | Publisher Full Text

28. Nelson DA, Pettifor JM, Barondess DA, et al:: Comparison of cross-sectional geometry of the proximal femur in white and black women from Detroit and Johannesburg. J Bone Miner Res. 2004; 19(4): 560-65. PubMed Abstract | Publisher Full Text 
29. Peacock M, Buckwalter KA, Persohn S, et al.: Race and sex differences in bone mineral density and geometry at the femur. Bone. 2009; 45(2): 218-25. PubMed Abstract | Publisher Full Text | Free Full Text

30. Saeed I, Carpenter RD, Leblanc AD, et al:: Quantitative computed tomography reveals the effects of race and sex on bone size and trabecular and cortical bone density. J Clin Densitom. 2009; 12(3): 330-6. PubMed Abstract | Publisher Full Text

31. Mikhail MB, Vaswani AN, Aloia JF: Racial differences in femoral dimensions and their relation to hip fracture. Osteoporos Int. 1996; 6(1): 22-4.

PubMed Abstract | Publisher Full Text

32. Karasik D, Dupuis J, Cupples LA, et al:: Bivariate linkage study of proximal hip geometry and body size indices: the Framingham study. Calcif Tissue Int. 2007; 81(3): 162-73.

PubMed Abstract | Publisher Full Text | Free Full Text

33. Riggs BL, Melton lii LJ 3rd, Robb RA, et al.: Population-based study of age and sex differences in bone volumetric density, size, geometry, and structure at different skeletal sites. J Bone Miner Res. 2004; 19(12): 1945-54. PubMed Abstract | Publisher Full Text

34. Kostamo T, Bourne RB, Whittaker JP, et al:: No difference in gender-specific hip replacement outcomes. Clin Orthop Relat Res. 2009; 467(1): 135-40. PubMed Abstract | Publisher Full Text | Free Full Text

35. MacDonald SJ, Charron KD, Bourne RB, et al:: The John Insall Award: genderspecific total knee replacement: prospectively collected clinical outcomes. Clin Orthop Relat Res. 2008; 466(11): 2612-6.

PubMed Abstract | Publisher Full Text | Free Full Text

36. Meta M, Lu Y, Keyak JH, et al:: Young-elderly differences in bone density, geometry and strength indices depend on proximal femur sub-region: a cross sectional study in Caucasian-American women. Bone. 2006; 39(1): 152-8. PubMed Abstract | Publisher Full Text | Free Full Text

37. Seeman E: From density to structure: growing up and growing old on the surfaces of bone. J Bone Miner Res. 1997; 12(4): 509-21. PubMed Abstract | Publisher Full Text

38. Petit MA, Beck TJ, Shults J, et al.: Proximal femur bone geometry is appropriately adapted to lean mass in overweight children and adolescents. Bone. 2005; 36(3): 568-76.

PubMed Abstract | Publisher Full Text

39. Petit MA, McKay HA, MacKelvie KJ, et al:: A randomized school-based jumping intervention confers site and maturity-specific benefits on bone structural properties in girls: a hip structural analysis study. J Bone Miner Res. 2002; 17(3): 363-72.

PubMed Abstract | Publisher Full Text
40. Van der Meulen MC, Ashford M Jr, Kiratli J, et al.: Determinants of femoral geometry and structure during adolescent growth. J Orthop Res. 1996; 14(1): 22-9. PubMed Abstract | Publisher Full Text

41. Demissie S, Dupuis J, Cupples LA, et al:: Proximal hip geometry is linked to several chromosomal regions: genome-wide linkage results from the Framingham Osteoporosis Study. Bone. 2007; 40(3): 743-50. PubMed Abstract | Publisher Full Text | Free Full Text

42. Yang YJ, Dvornyk V, Jian WX, et al:: Genetic and environmental correlations between bone phenotypes and anthropometric indices in Chinese. Osteoporos Int. 2005; 16(9): 1134-1140.

PubMed Abstract | Publisher Full Text

43. Malkin I, Ermakov S, Kobyliansky E, et al:: Strong association between polymorphisms in ANKH locus and skeletal size traits. Hum Genet. 2006; 120(1): 42-51.

PubMed Abstract | Publisher Full Text

44. McLaughlin JR, Lee KR: The outcome of total hip replacement in obese and non-obese patients at 10- to 18-years. J Bone Joint Surg Br. 2006; 88(10): 1286-92.

PubMed Abstract | Publisher Full Text

45. Andrew JG, Palan J, Kurup HV, et al:: Obesity in total hip replacement. J Bone Joint Surg Br. 2008; 90(4): 424-9.

PubMed Abstract | Publisher Full Text

46. Vresilovic EJ, Hozack WJ, Rothman RH: Incidence of thigh pain after uncemented total hip arthroplasty as a function of femoral stem size. J Arthroplasty. 1996; 11(3): 304-11. $J$ Arthroplasty. 1996; 11(3): 304-11.
PubMed Abstract | Publisher Full Text

47. Brown TE, Larson B, Shen F, et al.: Thigh pain after cementless total hip arthroplasty: evaluation and management. J Am Acad Orthop Surg. 2002; 10(6): 385-92.

PubMed Abstract

48. Burkat $\mathrm{BC}$, Bourne $\mathrm{RB}$, Rorabeck $\mathrm{CH}$, et al.: Thigh pain in cementless total hip arthroplasty. A comparison of two systems at 2 years' follow-up. Orthop Clin North Am. 1993; 24(4): 645-53. PubMed Abstract

49. Skinner HB, Curlin FJ: Decreased pain with lower flexural rigidity of uncemented femoral prostheses. Orthopedics. 1990; 13(11): 1223-8. PubMed Abstract

50. Moulton DL, Lindsey RW, Gugala Z: Dataset 1 in: Proximal Femur Size and Geometry in Cementless Total Hip Arthroplasty Patients. F1000Research. 2015 Data Source 


\section{Open Peer Review}

\section{Current Peer Review Status:}

\section{Version 1}

Reviewer Report 22 October 2015

https://doi.org/10.5256/f1000research.7038.r10680

(C) 2015 Noble P. This is an open access peer review report distributed under the terms of the Creative Commons Attribution License, which permits unrestricted use, distribution, and reproduction in any medium, provided the original work is properly cited.

\section{Philip C Noble}

Department of Orthopedics, Baylor College of Medicine, Houston, TX, USA

This is an interesting paper which addresses an important issue in joint replacement.

My comments /questions are as follows:

1. With several confounding variables it is not possible to draw robust generalizable conclusions without a much larger dataset (ie 100+ cases). This casts doubt on some of the comparisons that are deemed not statistically significant.

2. The authors state that a difference of at least $20 \%$ must be present between group averages for the comparison to be valid (ie adequately powered). Such a large value makes many of the comparisons impossible to generalize to other populations and reports.

3. The challenge with using clinical radiographs is guaranteeing the rotation of the femur projected on each AP exposure. As canal dimensions are sensitive to rotation, how was this achieved in this study?

4. Gender, age, and to some extent, race, have been widely documented as fundamentally affecting the shape of the femur. Therefore these variables must be treated separately as nominal variables and cannot be simply assumed to be "pseudo-continuous" in the analysis. This is particularly challenging due to the differential interactions of age and gender that occur because of the effect of menopause on female cortical morphology. Please describe how this challenge was handled in the statistical analysis which seems to lump all cases together.

Competing Interests: No competing interests were disclosed.

I confirm that I have read this submission and believe that I have an appropriate level of expertise to confirm that it is of an acceptable scientific standard, however I have significant reservations, as outlined above. 
Reviewer Report 01 July 2015

https://doi.org/10.5256/f1000research.7038.r9274

(C) 2015 Latta L. This is an open access peer review report distributed under the terms of the Creative Commons Attribution License, which permits unrestricted use, distribution, and reproduction in any medium, provided the original work is properly cited.

\section{Loren Latta}

Department of Orthopaedic Surgery, University of Miami, Miami, FL, USA

The only suggestion I have is to either call the "cortical thickness" measurement exactly what it is, or explain its limitations correctly.

1. It is a measure of the average thickness of the medial and lateral cortices from the radiographic view in the coronal plane.

2. Or, it is an estimate of the average thickness under the assumptions that the bone is circular in cross-section at this location and the thickness of the cortex is uniform throughout the cross-section.

I think \#1 is the best choice because neither of the assumptions given in \#2 are true, and it can be misleading to label that measurement an average of the total cortical thickness.

Competing Interests: No competing interests were disclosed.

I confirm that I have read this submission and believe that I have an appropriate level of expertise to confirm that it is of an acceptable scientific standard.

The benefits of publishing with F1000Research:

- Your article is published within days, with no editorial bias

- You can publish traditional articles, null/negative results, case reports, data notes and more

- The peer review process is transparent and collaborative

- Your article is indexed in PubMed after passing peer review

- Dedicated customer support at every stage

For pre-submission enquiries, contact research@f1000.com

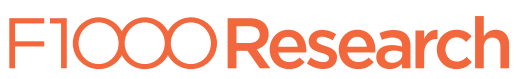

